\title{
Dynamic adsorption process of phthalate at goethite/aqueous interface: An ATR-FTIR study
}

\author{
Yanli Yang, Jingjing Du, Chuanyong Jing* \\ State Key Laboratory of Environmental Chemistry and Ecotoxicology, Research Center for Eco-Environmental Sciences, Chinese Academy of Sciences, Beijing \\ 100085, China
}

\section{H I G H L I G H T S}

- Phthalate adsorption at the goethite/aqueous interface was studied using ATR-FTIR.

- Phthalate form one outer-sphere and two bidentate inner-sphere surface complexes.

- Outer-sphere complex is suppressed with increasing ionic strength.

- Adsorption follow pseudo-secondorder kinetics and reach equilibrium within $60 \mathrm{~min}$

\section{A R T I C L E I N F O}

\section{Article history:}

Received 22 July 2013

Received in revised form

24 September 2013

Accepted 3 October 2013

Available online 12 October 2013

\section{Keywords:}

Phthalate

Goethite

ATR-FTIR spectroscopy

Surface complexation

Dynamic adsorption process
G R A P H I C A L A B S T R A C T

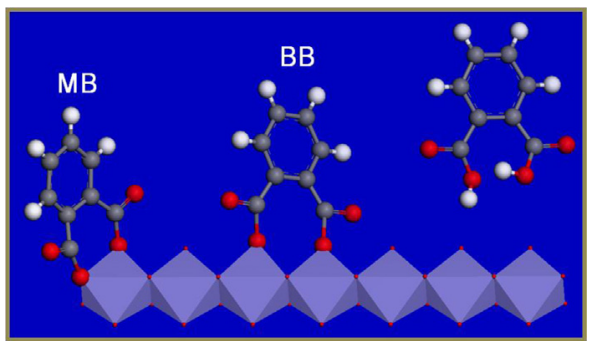

\begin{abstract}
A B S T R A C T
Insights into the molecular-level behaviors of phthalate at the goethite/aqueous interface can further our understanding of the fate and transport of natural organic matter analogs in the environment. The motivation of this work is to explore the interfacial configuration and dynamic adsorption process of phthalate on goethite at the molecular scale. The flow-cell ATR-FTIR measurement, curve-fitting analysis, and pseudosecond-order kinetic simulation were used to investigate the adsorption mechanisms. The results showed that phthalate formed one electrostatic outer-sphere complex and two inner-sphere configurations in mononuclear bidentate and binuclear bidentate structures. The contribution of outer-sphere complex to the overall phthalate adsorption was suppressed with increasing ionic strength and decreasing $\mathrm{pH}$ values. The ratio of adsorption capacity between these two inner-sphere configurations was slightly affected under different experimental conditions. Furthermore, the dynamic adsorption process of these three interfacial configurations followed the pseudo-second-order kinetics model, and reached equilibrium rapidly within $60 \mathrm{~min}$
\end{abstract}

(C) 2013 Elsevier B.V. All rights reserved.

\section{Introduction}

Phthalate is one of the ubiquitous low-molecular-weight carboxylic acid in the environment [1,2]. This carboxyl compound can readily adsorb onto minerals, thus altering its migration and susceptibility to transform in aquifers and soils. In addition, phthalate is deemed as an analog for natural organic matter (NOM) to investigate the mineral-NOM interactions, due to its high solubility in water, simple structure, as well as its similarity in functional

\footnotetext{
* Corresponding author. Tel.: +8610 62849523; fax: +86 1062849523.

E-mail address: cyjing@rcees.ac.cn (C. Jing).
}

groups to NOM [3-6]. Therefore, knowledge on the molecular-level mechanisms of phthalate adsorption is critical in understanding the interactions of NOM on minerals.

Extensive research has been conducted about phthalate adsorption on metal oxides using Fourier-transform infrared (FTIR) spectroscopy, but no consistent conclusion is obtained in its interfacial structure on the molecular level. For example, Tejedor-Tejedor [7] indicated that phthalate adsorbed on goethite in the form of mononuclear monodentate $(\mathrm{M}-\mathrm{M})$ and binuclear bidentate $(\mathrm{B}-\mathrm{B})$ structures involving only one carboxylate group bound to the surface iron. The $\mathrm{B}-\mathrm{B}$ configuration was also observed by Dobson and McQuillan [8] for phthalate adsorption on $\mathrm{TiO}_{2}, \mathrm{ZrO}_{2}, \mathrm{Al}_{2} \mathrm{O}_{3}$, and $\mathrm{Ta}_{2} \mathrm{O}_{5}$. However, Persson et al. $[9,10]$ proposed phthalate 
adsorption on boehmite, aged $\gamma-\mathrm{Al}_{2} \mathrm{O}_{3}$, and goethite in outersphere and mononuclear bidentate (M-B) structures. Furthermore, Hwang [1] found that phthalate formed three surface complexes on hematite, namely a fully deprotonated outer-sphere complex and two inner-sphere complexes with respect to a $\mathrm{M}-\mathrm{B}$ and a $\mathrm{B}-\mathrm{B}$ complex involving both carboxylate groups. The discrepancy in the proposed interfacial configuration motivated our further investigation at the molecular-scale understanding of phthalate adsorption. Here, goethite was chosen as the model adsorbent, due to its ubiquity in terrestrial soils and sediment [11,12]. Moreover, the existing literature on goethite provides valuable references for comparison $[7,10]$.

In this study, we investigated the adsorption mechanisms of phthalate at goethite/aqueous interface as a function of $\mathrm{pH}$ and ionic strength via in situ flow-cell measurements of attenuated total reflectance (ATR) FTIR spectroscopy. In addition to the determination of interfacial configurations, our current work focused on the dynamic process of phthalate adsorption on the basis of curve-fitting analysis and kinetic model simulation. These results could further our understanding of the fundamental interactions between NOM and iron oxide surfaces.

\section{Experimental}

\subsection{Materials}

High-purity phthalic acid was purchased from Sigma-Aldrich. All chemicals were analytical grade or higher and were used as received. The samples were prepared in Milli-Q water (18.2 M $\Omega$ ), which was boiled for 60 min and cooled with $\mathrm{N}_{2}$ purging to remove $\mathrm{CO}_{2}$. Goethite was synthetized and characterized as shown in our previous reports $[13,14]$. The goethite had a $\mathrm{N}_{2}$-BET surface area of $84.7 \mathrm{~m}^{2} / \mathrm{g}$ and a point of zero charge (PZC) of 8.9 .

\subsection{ATR-FTIR spectroscopy study}

The ATR-FTIR spectra were recorded with a Nicolet 6700 spectrometer equipped with a liquid-nitrogen cooled MCT detector. The ATR crystal, a $45^{\circ} \mathrm{ZnSe}$ or Ge crystal, was mounted in a flow cell (PIKE Technologies, USA). The pH range for ZnSe crystal was within 5-9, and the ZnSe crystal could be etched below $\mathrm{pH}$ 5. Then, Ge crystal was used when $\mathrm{pH}<5$. All spectra were averaged with 256 scans at $4 \mathrm{~cm}^{-1}$ resolution. Data collection and analysis were carried out with OMNIC software (Thermo Fisher Scientific Inc., USA). The numbers and positions of the frequency were justified using the second derivative. The curvefitting analysis of the overlap peak within the wavenumber range $1470-1330 \mathrm{~cm}^{-1}$ was conducted using the Gaussian line shape $[15,16]$.

The spectra of aqueous phthalate in $0.1 \mathrm{M} \mathrm{NaCl}$ solutions were obtained by subtracting the spectrum of background electrolyte solutions from the sample spectrum. The interfacial spectra of phthalate were measured with goethite film on the ZnSe crystal in the same way as our previous report [13,14]. Briefly, $400 \mu \mathrm{L}$ of goethite suspensions $(1 \mathrm{~g} / \mathrm{L})$ was spread on the crystal surface and dried in an oven at $50^{\circ} \mathrm{C}$ for $1 \mathrm{~h}$. Prior to use, the crystal was gently rinsed with Milli-Q water to remove loosely deposited goethite particles. Concentration of phthalic acid was fixed at $1 \mathrm{mM}$ in $0.01,0.1$, and $1 \mathrm{M} \mathrm{NaCl}$ solution. The background electrolyte was passed through the flow cell at the rate of $0.4 \mathrm{~mL} / \mathrm{min}$, and the background spectrum was collected until the equilibrium was established. The solution was then changed to the sample with the same $\mathrm{pH}$ value and $\mathrm{NaCl}$ concentration as that in the background. The adsorbed spectra were recorded as a function of time for $150 \mathrm{~min}$.
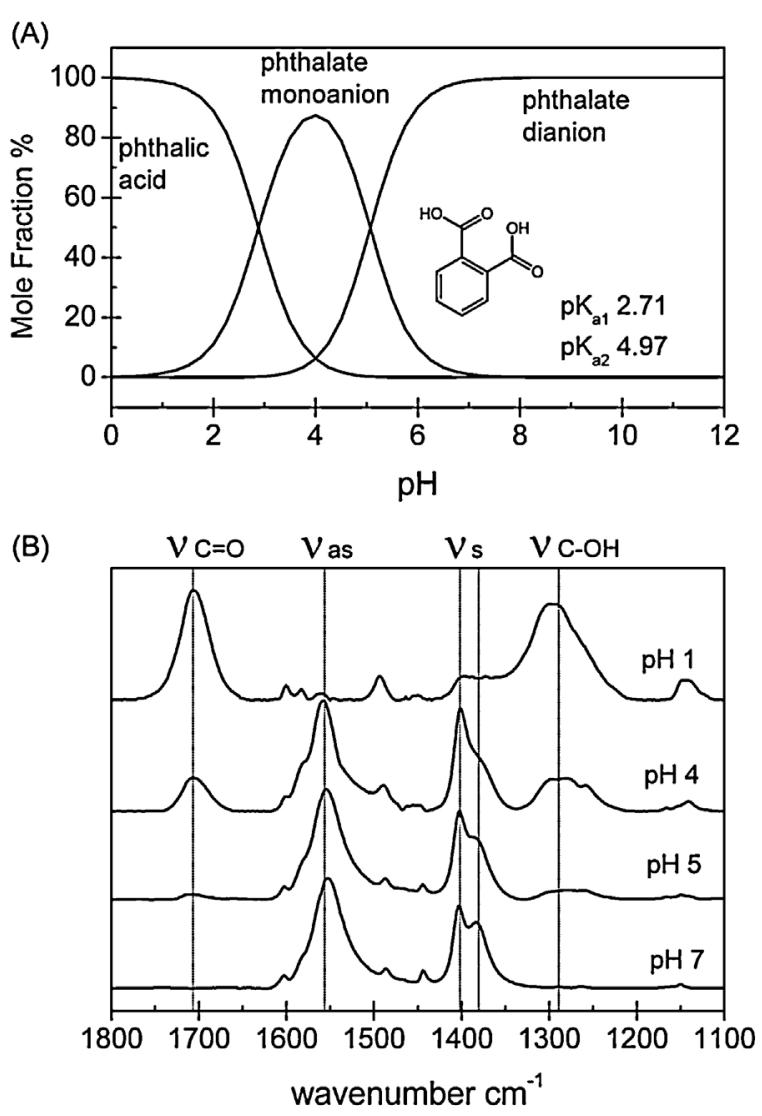

Fig. 1. (A) Distribution of phthalic acid, phthalate monoanion and dianion in solution as a function of $\mathrm{pH}$ at the ionic strength of $0.1 \mathrm{M}$. (B) FTIR spectra of $10 \mathrm{mM}$ dissolved phthalic acid at $\mathrm{pH} 1,4,5$, and 7 in $0.1 \mathrm{M} \mathrm{NaCl}$ solution. Spectra were normalized to the peak with the strongest intensity.

\section{Results and discussion}

\subsection{ATR-FTIR spectroscopy of dissolved phthalate}

Phthalic acid has two carboxylic groups with $\mathrm{p} K_{\mathrm{a} 1}=2.71$ and $\mathrm{p} K_{\mathrm{a} 2}=4.97$ at the ionic strength of $0.1 \mathrm{M}$, and thus exists as three aqueous species in the $\mathrm{pH}$ range $0-12$ (Fig. 1A). The spectra of soluble phthalate at $\mathrm{pH} 1,4$, and 7 in Fig. 1B represent the phthalic acid, monoanionic phthalate, and dianionic phthalate species, respectively. The observed frequencies and peak assignments of dissolved phthalate are list in Table 1.

As for phthalate dianion, the bands at 1485 and $1443 \mathrm{~cm}^{-1}$ were associated with benzene ring vibrations [1,7,17-19]. The two peaks at 1383 and $1402 \mathrm{~cm}^{-1}$ were clearly resolved in the characteristic symmetric $v_{\mathrm{COO}^{-}}$region $[1,9,19,20]$. Similarly, the second derivative of the strong peak in the asymmetric $v_{\mathrm{COO}^{-}}$region revealed two components at 1554 and $1564 \mathrm{~cm}^{-1}$, though it was seemed as a broad band at around $1552 \mathrm{~cm}^{-1}$ [9]. The appearance of asymmetric

Table 1

Peak positions and assignments for dissolved phthalate.

\begin{tabular}{llll}
\hline $\mathrm{pH} 1$ & $\mathrm{pH} 4$ & $\mathrm{pH} \mathrm{7}$ & Assignment \\
\hline 1709 & 1710 & & $v_{(\mathrm{C}=\mathrm{O})}$ \\
1565 & 1562 & 1564 & $v_{\mathrm{as}(\mathrm{COO})}$ \\
1556 & 1556 & 1554 & $v_{\mathrm{as}(\mathrm{COO})}$ \\
1494 & 1489 & 1485 & $v_{\mathrm{CC}(\mathrm{ring})}$ \\
1448 & 1445 & 1443 & $v_{\mathrm{CC}(\mathrm{ring})}$ \\
1402 & 1402 & 1402 & $v_{\mathrm{s}(\mathrm{COO})}$ \\
1386 & 1384 & 1383 & $v_{\mathrm{s}(\mathrm{COO})}$ \\
1290 & 1290 & & $v_{(\mathrm{C}-\mathrm{OH})}$ \\
\hline
\end{tabular}



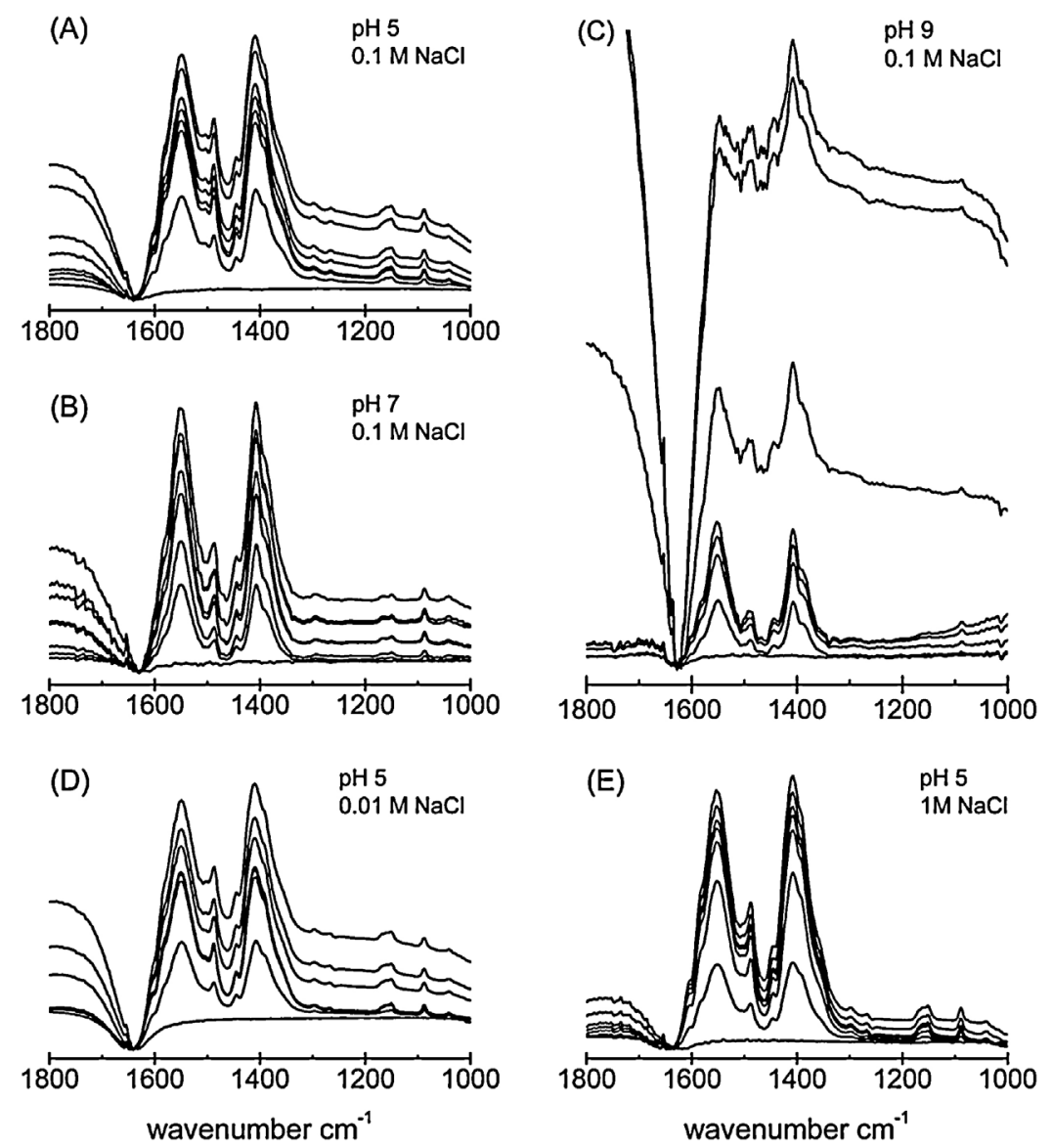

Fig. 2. The effect of $\mathrm{pH}$ and ionic strength on the dynamic spectra of adsorbed phthalate within $150 \mathrm{~min}$.

and symmetric vibration modes could be attributed to the two equivalent $\mathrm{COO}^{-}$groups which can move in cooperation or in opposition. The protonation of $\mathrm{COO}^{-}$could increase asymmetry in the molecular structure, resulting in one single bond and one double bond. Consequently, the formation of one $\mathrm{COOH}$ group in phthalate monoanion resulted in the intensity increase at $1710 \mathrm{~cm}^{-1}$ associated with $\mathrm{C}=\mathrm{O}$ stretch and a group of bands at $\sim 1290 \mathrm{~cm}^{-1}$ with $\mathrm{C}-\mathrm{OH}$ stretching vibration $[1,18]$. When fully protonated, the intensity of $\mathrm{COOH}$ vibrations further increased in accompany with a dramatic decrease in the intensity of $\mathrm{COO}^{-}$vibrations. Consequently, the bands at $\sim 1710$ and $1290 \mathrm{~cm}^{-1}$ could be considered as sensitive indicators for the protonation of phthalate [21]. Furthermore, the benzene ring vibrations shifted upwards to 1494 and $1448 \mathrm{~cm}^{-1}$ upon full protonation of two $\mathrm{COO}^{-}$groups.

\subsection{Spectra of adsorbed phthalate at interface}

In this study, we considered the effect of $\mathrm{pH}$ and ionic strength on the adsorption mechanisms of phthalate at goethite/aqueous interface (Fig. 2). Notably, the interfacial spectra from $\mathrm{pH} 9$ in $0.1 \mathrm{M}$ $\mathrm{NaCl}$ was in poor quality, due to the low adsorption capacity in basic conditions as well as the strong interference from vibrations associated with water. The limited adsorption capacity at high $\mathrm{pH}$ was also supported by the results of batch experiments in previous reports $[1,4,18,22,23]$.

As shown in Fig. 2, the surface complex remained unchanged during adsorption at a certain $\mathrm{pH}$ or ionic strength, as evidenced by the same peak positions resolved by the second derivative in the dynamic spectra. Furthermore, the interfacial spectra in all investigated conditions exhibited similar frequencies, indicating the same interfacial configurations under different $\mathrm{pH}$ and ionic strength.
The interfacial spectra under investigated conditions exhibited two strong and heavily overlapped bands within the range of $1650-1300 \mathrm{~cm}^{-1}$, which were roughly similar to that of phthalate dianion. Furthermore, contributions from the $\mathrm{COOH}$ vibrations of the protonated phthalate, i.e. $v_{\mathrm{C}=\mathrm{O}}$ at $\sim 1710 \mathrm{~cm}^{-1}$ and $v_{\mathrm{C}-\mathrm{OH}}$ at $\sim 1290 \mathrm{~cm}^{-1}$ were not evident, suggesting that the surface phthalate was in the dianionic form [1]. Notably, the spectra of dissolved phthalate at pH 5 represented spectroscopic feathers of monoanionic and dianionic phthalate species with relative content of $60 \%$ and $40 \%$, respectively (Fig. 1B). Then, the absence of $\mathrm{COOH}$ vibrations of adsorbed spectra indicated that the existence of innersphere adsorption [1]. Thus, the number and type of specific surface complexes deserve our further study.

\subsection{Determination of the interfacial configurations}

In this investigation, we focus on the analysis of symmetric $\mathrm{COO}^{-}$stretching region within $1460-1300 \mathrm{~cm}^{-1}$, because the interfacial spectra were strongly affected by the interference from vibrations associated with water. The intense of $\mathrm{H}-\mathrm{O}-\mathrm{H}$ bending vibrations are strongest near $1640 \mathrm{~cm}^{-1}$ and extend into the asymmetric $\mathrm{COO}^{-}$stretching region within $1600-1450 \mathrm{~cm}^{-1}$, strongly affecting the accuracy of analysis (i.e. determination of the overlapped bands, baseline normalization, and curve-fitting procedure). In contrast, the vibrations associated with water bending do not extend below $1450 \mathrm{~cm}^{-1}$ and thus do not impact the symmetric $\mathrm{COO}^{-}$stretch. Furthermore, the asymmetric and symmetric $\mathrm{COO}^{-}$ stretch vibrations appear in pairs, thus the surface complex could be determined from the number and positions of the symmetric $\mathrm{COO}^{-}$stretch vibrations. 


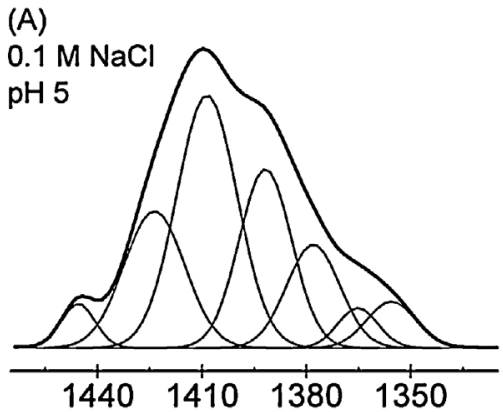

(B)

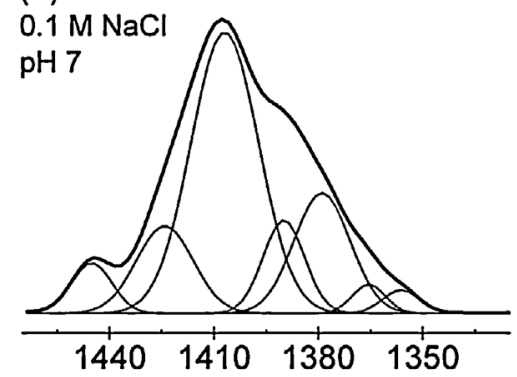

(C)

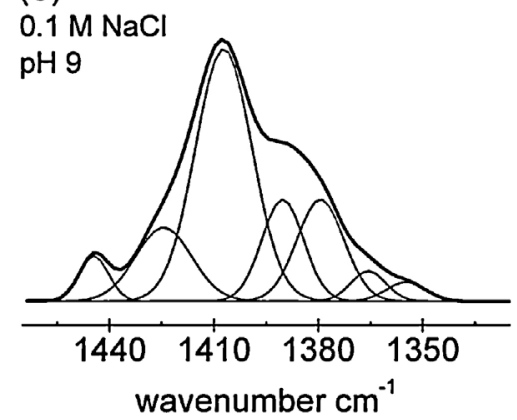

(D)

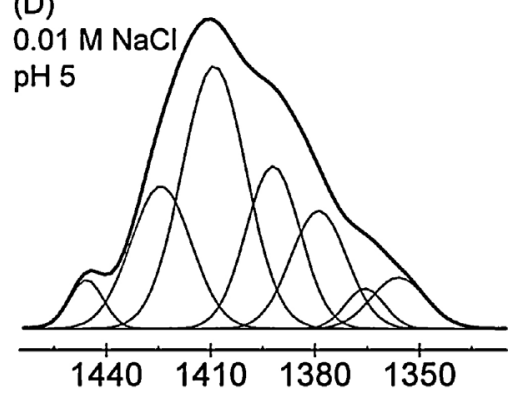

(E)

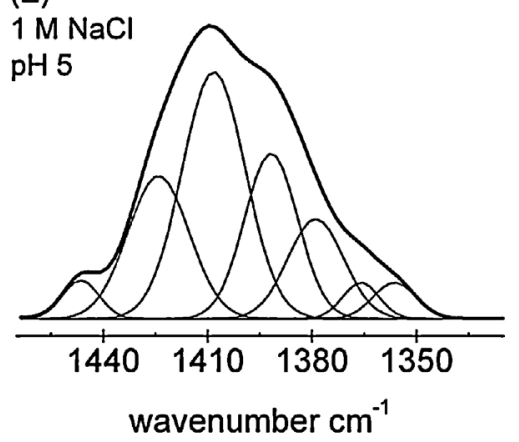

Fig. 3. Curve-fitting results of the overlapped peaks within $1450-1300 \mathrm{~cm}^{-1}$ from the time-dependent spectra collected at $150 \mathrm{~min}$.

Based on the second derivative method, the overlapped peaks within symmetric $\mathrm{COO}^{-}$stretching region were further analyzed by the curve fitting procedure in high quality $\left(r^{2}=0.99\right)$. The results of the spectra collected at 150 min were shown in Fig. 3 for illustration. The band centered at $\sim 1445 \mathrm{~cm}^{-1}$ was attributed to benzene ring vibrations [19]. As suggested by previous studies, the six bands at $\sim 1423,1407,1391,1378,1365$, and $1356 \mathrm{~cm}^{-1}$ should be all associated with symmetric $v_{\mathrm{S}\left(\mathrm{COO}^{-}\right)}$modes $[1,9,20]$. As discussed above, the adsorbed phthalate was in the dianionic form, indicating two symmetric $\mathrm{COO}^{-}$stretch vibrations in a certain surface complex. Consequently, six symmetric $\mathrm{COO}^{-}$stretch vibrations in this study suggested the existence of at least three surface complexes. The determination of interfacial configurations and peaks belonging to each structure were list in Table 2.

Table 2

Peak positions and assignments for adsorbed phthalate in outer-sphere, mononuclear bidentate (M-B), and binuclear bidentate (B-B) structures.

\begin{tabular}{llll}
\hline Outer-sphere & M-B & B-B & Assignment \\
\hline$\sim 1445$ & & $\sim 1423$ & $v_{\mathrm{CC}(\mathrm{rin})}$ \\
& & & $v_{\mathrm{s}(\mathrm{COO})}$ \\
$\sim 1407$ & $\sim 1391$ & & $v_{\mathrm{s}(\mathrm{COO})}$ \\
& & $v_{\mathrm{s}(\mathrm{COO})}$ \\
$\sim 1378$ & $\sim 1356$ & $\sim 1365$ & $v_{\mathrm{s}(\mathrm{COO})}$ \\
& & $v_{\mathrm{s}(\mathrm{COO})}$ \\
& & $v_{\mathrm{s}(\mathrm{COO})}$ \\
\hline
\end{tabular}

In line with previous studies, we also resolved the coexistence of outer-sphere and inner-sphere adsorption mechanisms of phthalate on goethite [22]. The bands centered at $\sim 1445,1407$ and $1378 \mathrm{~cm}^{-1}$ in the interfacial spectra were in close similarity to 1443,1402 and $1383 \mathrm{~cm}^{-1}$ of the phthalate dianion, which could be attributed to the outer-sphere complex [1]. The non-specific adsorption interactions were also observed for phthalate on iron and aluminum (hydr)oxides [1,9,20,22].

The other four peaks at $\sim 1423,1391,1365$, and $1356 \mathrm{~cm}^{-1}$ shifted significantly from that of the symmetric $v_{\mathrm{S}\left(\mathrm{COO}^{-}\right)}$vibrations of dissolved phthalate, corresponding to two inner-sphere complexes. These four bands were of similar peak positions with those of phthalate on hematite reported by Hwang et al. [1]. Compared with the frequencies of phthalate dianion, the symmetric $\mathrm{COO}^{-}$stretch vibrations of $\mathrm{M}-\mathrm{B}$ configuration shifted downwards to $\sim 1391$ and $1356 \mathrm{~cm}^{-1}$ [1]. In contrast, the two bands at $\sim 1423$ and $1365 \mathrm{~cm}^{-1}$ attributable to the B-B structure were shifted from $\sim 1402$ and $1383 \mathrm{~cm}^{-1}$ of the phthalate dianion, respectively [1]. Notably, the $\sim 1365 \mathrm{~cm}^{-1}$ peak was not resolved by Hwang by means of spectral subtraction, probably because of the weak intensity and close peak position in comparison with those of $\sim 1365 \mathrm{~cm}^{-1}$ (Fig. 3). Furthermore, the M-B and B-B type complexes coordinated to the surface iron via one oxygen atom from each $\mathrm{COO}^{-}$group of the phthalate dianion, due to the absence of bands at $\sim 1710$ and $1290 \mathrm{~cm}^{-1}$ associated with protonated $\mathrm{COOH}$ vibrations. 


\section{$I=0.1 \mathrm{M} \mathrm{NaCl}$}
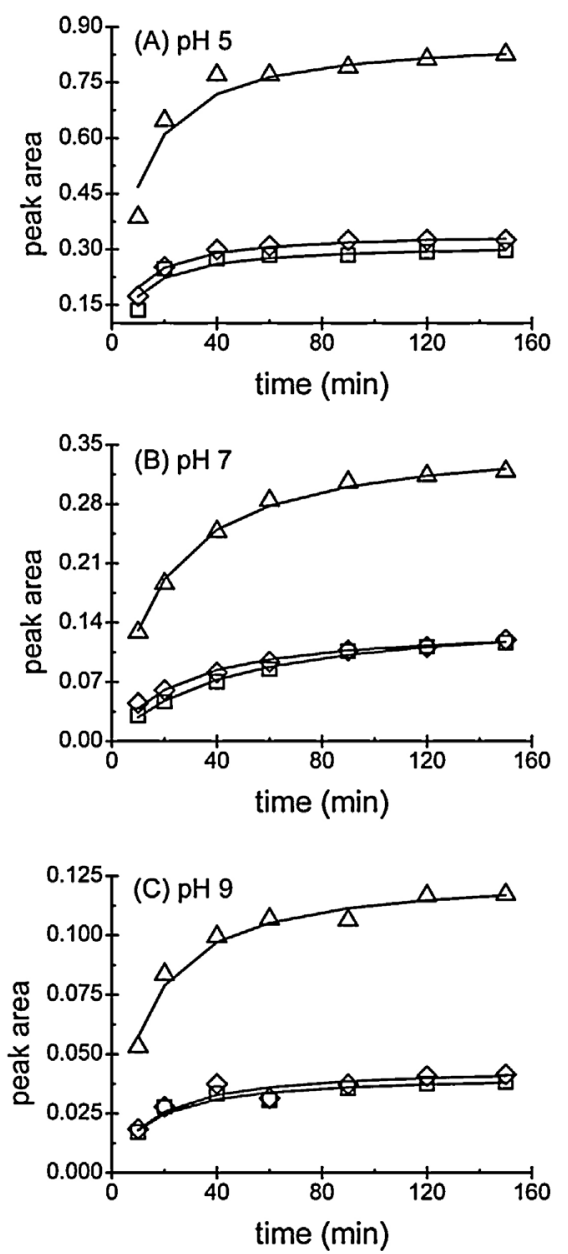

$\mathrm{pH}=5$
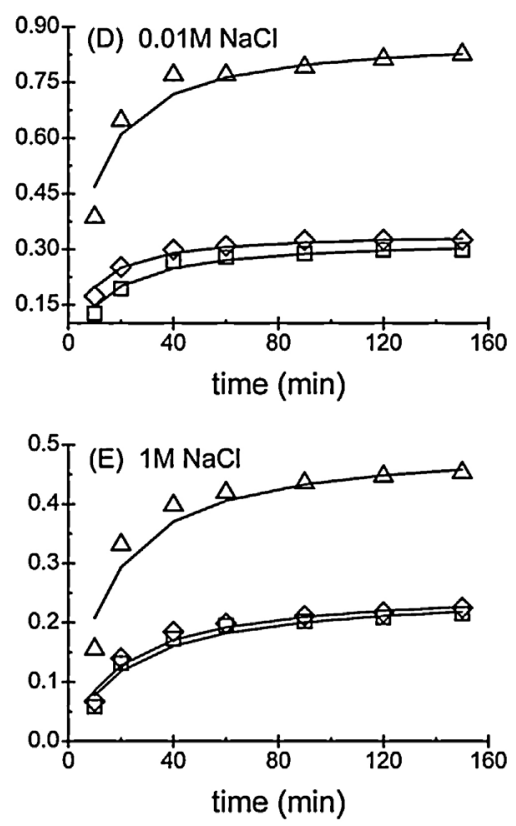

$$
\begin{array}{ll}
\square & \text { B-B } \sim 1423 \mathrm{~cm}^{-1} \\
\triangle & \text { outer-sphere } \sim 1407 \mathrm{~cm}^{-1} \\
\diamond & \text { M-B } \sim 1391 \mathrm{~cm}^{-1} \\
\text { pseudo-second-order kinetic } \\
\text { model }
\end{array}
$$

Fig. 4. Dynamic change in areas of the peak at $\sim 1423,1407$, and $1391 \mathrm{~cm}^{-1}$ under different $\mathrm{pH}$ and ionic strength.

\subsection{Dynamic adsorption process of phthalate on goethite}

The dynamic adsorption process for each interfacial configuration could be illustrated by monitoring the changes of their corresponding peak areas along with time [13,15,16,24]. The peak areas within the $1460-1300 \mathrm{~cm}^{-1}$ range were obtained via curve-fitting procedure. The fitting parameters, i.e. individual peak position and height, as well as full width at half maximum, were chosen on the basis of minimized residual between the overall fit and experimental spectrum. As shown in Fig. 4, the peaks at $\sim 1423$, 1407 , and $1391 \mathrm{~cm}^{-1}$ were selected for representing the B-B, outersphere, and M-B structures, respectively.

The three surface complexes exhibited similar adsorption behaviors in the dynamic process under all conditions. The adsorption capacity increased along with time and reached equilibrium rapidly within about $60 \mathrm{~min}$. Furthermore, the dynamic process of phthalate adsorption followed the pseudo-second-order kinetic model $[5,25,26]$ :

$\frac{t}{q_{t}}=\frac{1}{k q_{e}^{2}}+\frac{1}{q_{e}} t$

Here, $q_{t}$ is the peak area of a certain configuration at time $t ; q_{e}$ is the equilibrium uptake; $k$ is the equilibrium rate constant of pseudosecond-order kinetics. The values of $q_{e}$ and $k$ were calculated from the linear fitting parameters of $t / q_{t}$ versus $t$. The constant parameters and correlation coefficients were summarized in Table 3.

\subsection{The effect of $\mathrm{pH}$ and ionic strength on phthalate adsorption}

The three surface complexes were of different adsorption capacity as a function of $\mathrm{pH}$ and ionic strength, due to the uneven enhancement in the shape of overlapped peaks within the range of $1650-1300 \mathrm{~cm}^{-1}[13,24]$. The interfacial spectra were roughly similar to that of the phthalate dianion, suggesting that the outer-sphere adsorption was the dominant mechanisms on the molecular level. Furthermore, the strong dependence of macroscopic adsorption on $\mathrm{pH}$ and ionic strength also indicates the significant contribution of electrostatic interactions between phthalate and goethite surface.

As shown in Fig. 4, high $\mathrm{pH}$ suppressed the contribution of inner-sphere complex to the overall phthalate adsorption where the outer-sphere species are predominant, as evidenced by the ratio in peak areas of $\sim 1423,1407$, and $1391 \mathrm{~cm}^{-1}$ obtained at $150 \mathrm{~min}$ in $0.1 \mathrm{M} \mathrm{NaCl}$, i.e. $0.45: 1: 0.47$ ( $\mathrm{pH} \mathrm{5),} \mathrm{0.37:1:0.38} \mathrm{(pH} \mathrm{7),}$ and $0.33: 1: 0.35$ ( $\mathrm{pH} 9$ ). The inhibition of high $\mathrm{pH}$ on inner-sphere adsorption was also observed for other pure carboxylates such as tricarballylate [27]. Furthermore, the relative content of outersphere complex to the overall adsorption was decreased along with increasing ionic strength, which was evidenced by the ratios of the peak area of 1423,1407 , and $1391 \mathrm{~cm}^{-1}$ obtained at $150 \mathrm{~min}$, i.e. $0.36: 1: 0.39,0.45: 1: 0.47$, and $0.48: 1: 0.51$ for $\mathrm{pH} 5$ in 0.01 , and 0.1 , and $1 \mathrm{M} \mathrm{NaCl}$ solution, respectively. The decrease in the formation of outer-sphere complexes in high ionic strength could be attributed to the strong competition from chloride. However, no significant discrepancies were observed on the ratio of adsorption 
Table 3

Constant parameters and correlation coefficients for the pseudo-second-order kinetic model.

\begin{tabular}{|c|c|c|c|c|c|c|c|}
\hline & \multirow[t]{2}{*}{ Peak position $\left(\mathrm{cm}^{-1}\right)$} & \multicolumn{2}{|c|}{$0.01 \mathrm{M} \mathrm{NaCl}$} & \multicolumn{2}{|c|}{$0.1 \mathrm{M} \mathrm{NaCl}$} & \multicolumn{2}{|c|}{$1 \mathrm{M} \mathrm{NaCl}$} \\
\hline & & $r^{2}$ & $k$ & $r^{2}$ & $k$ & $r^{2}$ & $k$ \\
\hline \multirow{3}{*}{ pH 5} & $\sim 1423$ & 0.998 & 0.2398 & 0.9973 & 0.3894 & 0.9886 & 0.1784 \\
\hline & $\sim 1407$ & 0.9982 & 0.1323 & 0.9982 & 0.1324 & 0.9937 & 0.1413 \\
\hline & $\sim 1391$ & 0.9992 & 0.3846 & 0.9992 & 0.3846 & 0.9935 & 0.1938 \\
\hline \multirow{3}{*}{ pH 7} & 1423 & & & 0.9958 & 0.1539 & & \\
\hline & 1407 & & & 0.9994 & 0.1596 & & \\
\hline & 1390 & & & 0.9967 & 0.2911 & & \\
\hline \multirow{3}{*}{ pH 9} & 1423 & & & 0.9944 & 1.828 & & \\
\hline & 1406 & & & 0.9977 & 0.6572 & & \\
\hline & 1390 & & & 0.9882 & 1.5155 & & \\
\hline
\end{tabular}

Note. $r$ and $k$ refer to the correlation coefficient and equilibrium rate constant, respectively.

capacity between M-B and B-B inner-sphere configurations under different $\mathrm{pH}$ and ionic strength conditions.

\section{Conclusions}

The dynamic adsorption process of phthalate at goethite/aqueous interface was investigated via ATR-FTIR flow-cell measurement under different $\mathrm{pH}$ and ionic strength. The interfacial spectra with $1 \mathrm{mM}$ phthalate in 0.01 and $0.1 \mathrm{M} \mathrm{NaCl}$ resolved the coexistence of one outer-sphere and two inner-sphere surface complexes. The outer-sphere complex adsorbed on goethite via electrostatic interactions, and the inner-sphere complexes were in $\mathrm{M}-\mathrm{B}$ and $\mathrm{B}-\mathrm{B}$ structures with one oxygen atom from each $\mathrm{COO}^{-}$ group of the phthalate dianion coordinated to the surface iron. As for the dynamic process, the three surface complexes reached adsorption equilibrium rapidly within about $60 \mathrm{~min}$, and could be well described by the pseudo-second-order kinetics model. The results provide insights into the molecular-level mechanisms of phthalate adsorption on goethite, facilitating description and prediction of the behaviors of NOM in the environmental.

\section{Acknowledgement}

We acknowledge the financial support of the National Natural Science Foundation of China (41023005, 41373123 and 21321004).

\section{Appendix A. Supplementary data}

Supplementary data associated with this article can be found, in the online version, at http://dx.doi.org/10.1016/j.colsurfa. 2013.10.021.

\section{References}

[1] Y.S. Hwang, J. Liu, J.J. Lenhart, C.M. Hadad, Surface complexes of phthalic acid at the hematite/water interface, J. Colloid Interface Sci. 307 (2007) 124-134.

[2] B.W. Strobel, Influence of vegetation on low-molecular-weight carboxylic acids in soil solution-a review, Geoderma 99 (2001) 169-198.

[3] C.C. Trout, J.D. Kubicki, UV resonance Raman spectra and molecular orbital calculations of salicylic and phthalic acids complexed to $\mathrm{Al}^{3+}$ in solution and on mineral surfaces, J. Phys. Chem. A 108 (2004) 11580-11590.

[4] C.R. Evanko, D.A. Dzombak, Influence of structural features on sorption of NOManalogue organic acids to goethite, Environ. Sci. Technol. 32 (1998) 2846-2855.

[5] X.H. Guan, G.H. Chen, C. Shang, Combining kinetic investigation with surface spectroscopic examination to study the role of aromatic carboxyl groups in NOM adsorption by aluminum hydroxide, J. Colloid Interface Sci. 301 (2006) 419-427.

[6] X.H. Guan, C. Shang, G.H. Chen, Competitive adsorption of organic matter with phosphate on aluminum hydroxide, J. Colloid Interface Sci. 296 (2006) 51-58.

[7] M.I. Tejedor-Tejedor, E.C. Yost, M.A. Anderson, Characterization of benzoic and phenolic complexes at the goethite/aqueous solution interface using cylindrical internal reflection Fourier transform infrared spectroscopy. 2. Bonding structures, Langmuir 8 (1992) 525-533.

[8] K.D. Dobson, A.J. McQuillan, In situ infrared spectroscopic analysis of the adsorption of aromatic carboxylic acids to $\mathrm{TiO}_{2}, \mathrm{ZrO}_{2}, \mathrm{Al}_{2} \mathrm{O}_{3}$, and $\mathrm{Ta}_{2} \mathrm{O}_{5}$ from aqueous solutions, Spectrochim. Acta A 56 (2000) 557-565.

[9] J. Nordin, P. Persson, E. Laiti, S. Sjöberg, Adsorption of o-phthalate at the water-boehmite $(\gamma-\mathrm{AlOOH})$ interface: evidence for two coordination modes, Langmuir 13 (1997) 4085-4093.

[10] P. Persson, J. Nordin, J. Rosenqvist, L. Lövgren, L.O. Öhman, S. Sjöberg, Comparison of the adsorption of o-phthalate on boehmite $(\gamma-\mathrm{AlOOH})$, aged $\gamma-\mathrm{Al}_{2} \mathrm{O}_{3}$, and goethite ( $\alpha$-FeOOH), J. Colloid Interface Sci. 206 (1998) 252-266.

[11] S. Kang, D. Amarasiriwardena, B. Xing, Effect of dehydration on dicarboxylic acid coordination at goethite/water interface, Colloids Surf. A 318 (2008) 275-284.

[12] A.J.A. Aquino, D. Tunega, G. Haberhauer, M.H. Gerzabek, H. Lischka, Acid-base properties of a goethite surface model: a theoretical view, Geochim. Cosmochim. Acta 72 (2008) 3587-3602.

[13] Y. Yang, W. Yan, C. Jing, Dynamic adsorption of catechol at the goethite/aqueous solution interface: a molecular-scale study, Langmuir 28 (2012) 14588-14597.

[14] Y. Yang, J. Duan, C. Jing, Molecular-scale study of salicylate adsorption and competition with catechol at goethite/aqueous solution interface, J. Phys. Chem. C 117 (2013) 10597-10606.

[15] S.J. Hug, In situ Fourier transform infrared measurements of sulfate adsorption on hematite in aqueous solutions, J. Colloid Interface Sci. 188 (1997) 415-422.

[16] J. Ha, T. Hyun Yoon, Y. Wang, C.B. Musgrave, J.G.E. Brown, Adsorption of organic matter at mineral/water interfaces: 7. ATR-FTIR and quantum chemical study of lactate interactions with hematite nanoparticles, Langmuir 24 (2008) 6683-6692.

[17] J.S. Loring, M. Karlsson, W.R. Fawcett, W.H. Casey, Infrared spectra of phthalic acid, the hydrogen phthalate ion, and the phthalate ion in aqueous solution, Spectrochim. Acta A 57 (2001) 1635-1642.

[18] M.R. Das, S. Mahiuddin, The influence of functionality on the adsorption of phydroxy benzoate and phthalate at the hematite-electrolyte interface, J. Colloid Interface Sci. 306 (2007) 205-215.

[19] S. Tunesi, M.A. Anderson, Surface effects in photochemistry: an in situ cylindrical internal reflection-Fourier transform infrared investigation of the effect of ring substituents on chemisorption onto titania ceramic membranes, Langmuir 8 (1992) 487-495.

[20] O. Klug, W. Forsling, A spectroscopic study of phthalate adsorption on $\gamma$ aluminum oxide, Langmuir 15 (1999) 6961-6968.

[21] P.M. Morris, R.A. Wogelius, Phthalic acid complexation and the dissolution of forsteritic glass studied via in situ FTIR and X-ray scattering, Geochim. Cosmochim. Acta 72 (2008) 1970-1985.

[22] J.F. Boily, P. Persson, S. Sjöberg, Benzenecarboxylate surface complexation at the goethite $(\alpha-\mathrm{FeOOH}) /$ water interface: II. Linking IR spectroscopic observations to mechanistic surface complexation models for phthalate, trimellitate, and pyromellitate, Geochim. Cosmochim. Acta 64 (2000) 3453-3470.

[23] J.F. Boily, P. Persson, S. Sjöberg, Benzenecarboxylate surface complexation at the goethite $(\alpha-\mathrm{FeOOH}) /$ water interface: III. The influence of particle surface area and the significance of modeling parameters, J. Colloid Interface Sci. 227 (2000) 132-140.

[24] K. Axe, M. Vejgården, P. Persson, An ATR-FTIR spectroscopic study of the competitive adsorption between oxalate and malonate at the water-goethite interface, J. Colloid Interface Sci. 294 (2006) 31-37.

[25] Y. Liu, New insights into pseudo-second-order kinetic equation for adsorption, Colloids Surf. A 320 (2008) 275-278.

[26] M. Yurdakoç, Y. Seki, S. Karahan, K. Yurdakoç, Kinetic and thermodynamic studies of boron removal by Siral 5, Siral 40, and Siral 80, J. Colloid Interface Sci. 286 (2005) 440-446.

[27] M. Lindegren, J.S. Loring, P. Persson, Molecular structures of citrate and tricarballylate adsorbed on $\alpha-\mathrm{FeOOH}$ particles in aqueous suspensions, Langmuir 25 (2009) 10639-10647. 